Volume 2 Nomor 2, Edisi Desember 2019

Prodi PGSD Universitas Slamet Riyadi

ISSN 2620-6560 (print) ISSN 2620-746X (online)

\title{
PENGEMBANGAN CD INTERAKTIF MACROMEDIA FLASH BERBASIS NILAI KARAKTER SUBTEMA 1 AKU DAN CITA-CITAKU KELAS IV
}

\author{
Ulfah Fitria Setiyani $^{1}$, Arfilia Wijayanti ${ }^{2}$, Filia Prima Artharina ${ }^{3}$ \\ Fakultas Ilmu Pendidikan, Universitas PGRI Semarang \\ Email: ulfahfitria.s@gmail.com
}

\begin{abstract}
The background that drives this research was the lack of 2013 curriculum learning media in the form of technology-based applications. The purpose of the study determined the feasibility of media-based interactive CD macromedia flash media. The type of research used is Research and Development (RnD) with the ADDIE model. Data analysis techniques used descriptive qualitative and quantitative descriptive. The results of the feasibility based on data analysis by expert experts obtain an average percentage of $94.17 \%$ for media feasibility, 95.00\% for material feasibility and $91.67 \%$ for the feasibility of character values. The acquisition of teacher responses to media acceptance obtained a percentage in SD N Sawah Besar 02 of $86.67 \%$, Elementary School of Muhajirin at $100.00 \%$ and SD N Siwalan obtained a percentage of $96.67 \%$. The results of the questionnaire responses of the students obtained $96.36 \%$ in SD N Sawah Besar 02 and 93.64\% in the Primary Schools of the Muhajirin. Media based on interactive CD macromedia flash based on the value of the character of subtheme I and my ideals have met the criteria very well and are worthy of being used in the learning process.
\end{abstract}

Keywords: development, media, interactive CD, Macromedia Flash, character value

\begin{abstract}
Abstrak
Latar belakang yang mendorong dalam penelitian ini adalah kurangnya media pembelajaran kurikulum 2013 yang berupa aplikasi berbasis teknologi. Adapun tujuan penelitian untuk mengetahui kelayakan media CD interaktif macromedia flash berbasis nilai karakter. Jenis penelitian yang digunakan yaitu Research and Development (RnD) dengan model ADDIE. Teknik analisis data menggunakan deskriptif kualitatif dan deskriptif kuantitatif. Hasil kelayakan berdasarkan analisis data oleh pakar ahli memperoleh rata-rata presentase sebesar 94,17\% untuk kelayakan media, 95,00\% untuk kelayakan materi dan 91,67\% untuk kelayakan nilai karakter. Perolehan tanggapan guru terhadap keberterimaan media memperoleh presentase di SD N Sawah Besar 02 sebesar 86,67\%, SD IP Muhajirin sebesar $100,00 \%$ dan SD N Siwalan memperoleh presentase sebesar 96,67\%. Hasil angket tanggapan siswa memperoleh 96,36\% di SD N Sawah Besar 02 dan 93,64\% di SD IP Muhajirin. Media CD interaktif macromedia flash berbasis nilai karakter subtema 1 aku dan cita-citaku telah memenuhi kriteria sangat baik dan layak digunakan dalam proses pembelajaran.
\end{abstract}

Kata kunci: Pengembangan, Media, CD Interaktif, Macromedia Flash, Nilai Karakter 


\section{PENDAHULUAN}

Seperti yang termuat dalam Undang-Undang Sistem Pendidikan Nasional No.20 tahun 2003 bahwa tujuan dari pendidikan nasional yaitu untuk mengembangkan potensi dalam diri siswa agar menjadi manusia yang beriman dan bertaqwa kepada Tuhan Yang Maha Esa, berakhlak mulia, berilmu, cakap, kreatif, mandiri dan menjadi warga negara yang demokratif, serta bertanggung jawab. Dalam merealisasikan tujuan pendidikan nasional tersebut berbagai usaha dilakukan pemerintah dalam mengoptimalkan kualitas pendidikan. Salah satunya adalah dikembangkannya kurikulum 2013. Hal ini sesuai dengan pernyataan Rusman (2015:92) bahwa kurikulum 2013 bertujuan untuk melahirkan generasi penerus bangsa yang memiliki kemampuan produktif, kreatif dan berkarakter.

Pelaksanaan kurikulum 2013 berbeda dengan kurikulum lainnya, guru harus menjadi fasilitator pembelajaran dengan mengintegrasikan kecakapan abad 21 pada proses pembelajaran bagi peserta didik. Hal tersebut sesuai dengan pernyataan Rusman (2013: 16) bahwa era transformasi pendidikan abad-21 guru perlu mengikuti perkembangan zaman, begitu juga dengan siswa perlu belajar sesuai dengan zamannya. Permasalahan penting pembelajaran abad-21 ialah pengintegrasian teknologi komputer dalam kegiatan pembelajaran adalah keniscayaan. Dengan teknologi ini dapat membuat pembelajaran lebih aktif, kreatif, inovatif dan menyenangkan, sehingga terciptanya multi interaksi, baik antara guru, siswa dengan media dan sumber belajar, maupun siswa dengan siswa lainnya.

Penggunaan media pembelajaran sangatlah dibutuhkan agar pembelajaran lebih aktif, kreatif, inovatif dan menyenangkan. Hal ini sejalan dengan pernyataan Arsyad (2014: 29) bahwa manfaat dari media pembelajaran tidak hanya sebagai penyampaian informasi namun juga dapat meningkatkan dan mengarahkan perhatian siswa sehingga menimbulkan motivasi belajar, interaksi siswa menimbulkan 
kemandirian belajar siswa yang sesuai dengan kemampuan dan minatnya. Dengan kata lain, bahwa media merupakan suatu bagian yang tidak dapat dipisahkan dalam proses kegiatan pembelajaran. Adanya keterlibatan penggunaan media pembelajaran merupakan upaya kreatif dari seorang guru untuk menciptakan pengalaman belajar yang bermakna bagi siswa.

Berdasarkan hasil wawancara dengan guru kelas IV yang dilakukan di tiga Sekolah Dasar. Yaitu SD Islam Plus Muhajirin dengan narasumber Bapak Agung Triwidodo, S.Pd, SD N Siwalan dengan narasumber Ibu Nuryanti, S.Pd, dan SD N Sawah Besar 02 dengan narasumber Bapak Marsoyo, S.Pd. Ketiga narasumber menyatakan bahwa dalam pembelajaran disekolah dasar sesungguhnya guru masih belum menggunakan media pembelajaran di setiap kesempatan karena berbagai faktor. Kurangnya pemahaman guru untuk mengoperasikan komputer, keterbatasan waktu dalam merancang dan menyiapkan media dan tidak tersedianya media yang sesuai kebutuhan. Guru mengakui pentingnya peran media pembelajaran dalam menunjang proses belajar mengajar. Pemicu utama masalah ini adalah guru kurang melibatkan media pembelajaran tematik khususnya media yang memanfaatkan teknologi dengan berbasis nilai karakter disebabkan oleh kurangnya kemampuan guru untuk mengoperasikan komputer.

Hasil observasi menyatakan bahwa media yang memanfaatkan komputer masih jarang digunakan dalam proses belajar mengajar karena tidak tersedianya proyektor tetap di kelas serta tidak tersedianya waktu guru dalam menyiapkan bahan yang digunakan sehingga penggunaan proyektor dan media dengan memanfaatkan komputer kurang maksimal. Dan media yang berbasis nilai karakter guru belum pernah menggunakan. Hal ini seperti yang diungkap oleh Bapak Marsoyo, S.Pd pada saat observasi awal.

Berdasarkan hasil observasi, peneliti berinovasi untuk mengembangkan media pembelajaran tematik dengan melibatkan pemanfaatan komputer dan menanamkan nilai karakter siswa 
yaitu menggunakan media pembelajaran CD interaktif. Salah satu aplikasi yang dapat digunakan dalam membantu membuat media CD interaktif adalah macromedia flash. Macromedia flash peneliti pilih sebagai software untuk mengembangkan media pembelajaran ini karena memiliki beberapa kelebihan. Hal ini sejalan dengan hasil penelitian Kusumawati (2015) menyatakan bahwa kondisi siswa saat mengikuti pembelajaran dengan media mendapatkan respon positif, antusias yang sangat baik dan siswa ingin menggunakan media ini lagi untuk pembelajaran selanjutnya.

Pembelajaran

berbasis

multimedia seperti ini tentunya dapat menyajikan materi pelajaran yang lebih menarik dan tidak monoton sehingga peserta didik dapat mempelajari materi pelajaran tertentu secara mandiri dengan komputer yang dilengkapi dengan multimedia tersebut. Hal tersebut sesuai dengan pernyataan Anggra (2008: 11) bahwa macromedia flash adalah sebuah program grafik dan animasi yang keberadaannya ditujukan bagi pecinta desain dan animasi untuk berkreasi membuat animasi web interaktif, film animasi kartun, presentasi bisnis atau kegiatan, company/organization profile dan game flash yang menarik. Demikian, faktor utama yang melatarbelakangi peneliti untuk mengadakan penelitian yang berjudul "Pengembangan CD Interaktif Macromedia Flash Berbasis Nilai Karakter Subtema 1 Aku dan CitaCitaku Kelas IV Sekolah Dasar"

\section{METODE PENELITIAN}

Metode penelitian yang digunakan yaitu Research and Development. Menurut pandangan Sugiyono (2017: 30) penelitian dan pengembangan (Research and Development) adalah dapat diartikan sebagai cara ilmiah untuk meneliti, merancang, memproduksi, dan menguji validitas produk yang telah dihasilkan. Model yang digunakan ialah model ADDIE yang dikembangkan oleh Dick and Carry. Uji kelayakan mengenai pengembangan produk media $\mathrm{CD}$ interaktif macromedia flash berbasis nilai karakter dilakukan dengan pemberian kuisioner (angket) 
mengenai kelayakan media, materi pembelajaran dan karakter oleh validator Dosen Ahli, kuisioner (angket) tanggapan siswa dan guru untuk keberterimaan media pada tahap uji coba lapangan.

Uji coba lapangan dilakukan di 2 Sekolah Dasar yang meliputi SD N Sawah Besar 02 Semarang dengan sample 25 siswa dan SD Islam Plus Muhajirin Semarang dengan sample 24 siswa yang dilakukan pada tanggal 12-15 April 2019. Tahapan uji coba lapangan dilakukan apabila produk media yang dikembangkan telah dinyatakan layak oleh validator Dosen ahli. Teknik pengumpulan data yang dilakukan oleh peneliti berupa data kualitatif dan kuantitatif sebagai berikut:

Tabel 1. Teknik Pengumpulan Data

\begin{tabular}{|c|c|c|c|c|c|}
\hline $\begin{array}{l}\mathbf{N} \\
\text { o. }\end{array}$ & Data & Teknik & Waktu & $\begin{array}{c}\text { Sasar } \\
\text { an }\end{array}$ & Tujuan \\
\hline 1. & $\begin{array}{l}\text { Kualitat } \\
\text { if }\end{array}$ & $\begin{array}{l}\text { Wawanc } \\
\text { ara }\end{array}$ & $\begin{array}{l}\text { Studi } \\
\text { Pendahulu } \\
\text { an }\end{array}$ & $\begin{array}{l}\text { Guru } \\
\text { Kelas } \\
\text { IV }\end{array}$ & $\begin{array}{l}\text { Untuk } \\
\text { mengeta } \\
\text { hui } \\
\text { potensi } \\
\text { dan } \\
\text { masalah }\end{array}$ \\
\hline 2. & $\begin{array}{l}\text { Kuantit } \\
\text { atif }\end{array}$ & Angket & $\begin{array}{l}\text { Studi } \\
\text { pengemba } \\
\text { ngan dan } \\
\text { pada tahap } \\
\text { uji coba } \\
\text { pengemba } \\
\text { ngan } \\
\text { produk }\end{array}$ & $\begin{array}{l}\text { Ahli } \\
\text { media } \\
\text {, ahli } \\
\text { materi } \\
\text {, ahli } \\
\text { karakt } \\
\text { er dan } \\
\text { siswa } \\
\text { kelas } \\
\text { IV }\end{array}$ & $\begin{array}{l}\text { Untuk } \\
\text { mengeta } \\
\text { hui } \\
\text { kelayak } \\
\text { an } \\
\text { produk } \\
\text { media }\end{array}$ \\
\hline
\end{tabular}

Perolehan analisis data dilakukan secara deskriptif kualitatif dan kuantitatif. Skor penilaian kuisioner menggunakan skala Likert pada kuisioner instrumen validasi dan keberterimaan media. Sedangkan, skala Guttman diberikan pada kuisioner tanggapan siswa. Skala Guttman hanya menghadirkan sejumlah pertanyaan berupa positif (1) dan negatif (0) dalam suatu obyek sedangkan skala Likert yaitu dengan menghadirkan pilihan jawaban melalui skor nilai meliputi "4 (sangat baik), 3 (baik), 2 (cukup), dan 1 (kurang)." Perhitungan presentase kelayakan dari hasil analisis data dilakukan dengan acuan rumus yang dikemukakan oleh Arikunto (2013) yaitu dengan cara:

Presentase $(\%)=\frac{\text { Jumlah Skor Total }(x)}{\text { Jumlah Skor Maximum }(x i)} \times 100 \%$ Untuk mengetahui penilaian kelayakan produk pengembangan maka dibutuhkan intrepretasi kriteria penilaian. Dalam hal ini menggunakan nilai presentase yang dikemukakan oleh Arikunto (2013: 44) sebagai kriteria penilaian kelayakan pada tabel dibawah ini:

Tabel 2. Kriteria Penilaian Kelayakan

\begin{tabular}{cc}
\hline Interpretasi & Kriteria \\
\hline $81 \%-100 \%$ & Sangat Baik \\
$61 \%-80 \%$ & Baik \\
$41 \%-60 \%$ & Cukup \\
$21 \%-40 \%$ & Kurang \\
$0 \%-20 \%$ & Sangat Kurang \\
\hline
\end{tabular}




\section{HASIL DAN PEMBAHASAN}

Uji kelayakan media CD interaktif macromedia flash berbasis nilai karakter divalidator oleh 4 Dosen ahli (3 Dosen ahli media dan materi pembelajaran, 1 Dosen ahli karakter). Tahapan ini dilakukan untuk mengetahui kelayakan media $\mathrm{CD}$ interaktif macromedia flash berbasis nilai karakter sebelum digunakan pada tahap uji coba lapangan yang bertujuan untuk mengetahui tanggapan penggunaan media pada proses pembelajaran. Perolehan validasi kelayakan media dan materi dapat dilihat pada tabel berikut ini:

Tabel 3. Kelayakan Media

\begin{tabular}{|c|c|c|c|c|c|c|c|}
\hline \multirow{3}{*}{ No. } & \multirow{3}{*}{$\begin{array}{c}\text { Aspek } \\
\text { Kriteria }\end{array}$} & \multicolumn{6}{|c|}{ Penilaian Validasi } \\
\hline & & Media 1 & Media 1 & Media 2 & Media 2 & Media 3 & Media 3 \\
\hline & & Tahap I & Tahap II & Tahap I & Tahap II & Tahap I & Tahap II \\
\hline 1. & Psikologis & $58,33 \%$ & $91,67 \%$ & $58,33 \%$ & $100,00 \%$ & $66,67 \%$ & $100,00 \%$ \\
\hline 2. & Organisasi isi & $65,00 \%$ & $95,00 \%$ & $60,00 \%$ & $95,00 \%$ & $65,00 \%$ & $90,00 \%$ \\
\hline 3. & Penyajian & $66,66 \%$ & $100,00 \%$ & $66,67 \%$ & $100,00 \%$ & $66,67 \%$ & $83,33 \%$ \\
\hline 4. & $\begin{array}{l}\text { Penggunaan } \\
\text { media }\end{array}$ & $58,33 \%$ & $91,67 \%$ & $66,67 \%$ & $83,33 \%$ & $75,00 \%$ & $100,00 \%$ \\
\hline 5. & $\begin{array}{l}\text { Prinsip audio } \\
\text { visual }\end{array}$ & $65,00 \%$ & $95,00 \%$ & $60,00 \%$ & $100,00 \%$ & $70,00 \%$ & $85,00 \%$ \\
\hline 6. & $\begin{array}{l}\text { Prinsip } \\
\text { komputer }\end{array}$ & $75,00 \%$ & $100,00 \%$ & $50,00 \%$ & $100,00 \%$ & $75,00 \%$ & $100,00 \%$ \\
\hline & Kriteria & Baik & $\begin{array}{l}\text { Sangat } \\
\text { Baik }\end{array}$ & Baik & $\begin{array}{c}\text { Sangat } \\
\text { Baik }\end{array}$ & Baik & $\begin{array}{c}\text { Sangat } \\
\text { Baik }\end{array}$ \\
\hline
\end{tabular}

Tabel 4. Kelayakan Materi

\begin{tabular}{cccccccc}
\hline \multirow{2}{*}{ No. } & \multirow{2}{*}{$\begin{array}{c}\text { Aspek } \\
\text { Kriteria }\end{array}$} & $\begin{array}{c}\text { Materi 1 } \\
\text { Tahap I }\end{array}$ & $\begin{array}{c}\text { Materi 1 } \\
\text { Tahap II }\end{array}$ & $\begin{array}{c}\text { Materi 2 } \\
\text { Tahap I }\end{array}$ & $\begin{array}{c}\text { Materi 2 } \\
\text { Tahap II }\end{array}$ & $\begin{array}{c}\text { Materi 3 } \\
\text { Tahap I }\end{array}$ & $\begin{array}{c}\text { Materi 3 } \\
\text { Tahap II }\end{array}$ \\
\cline { 3 - 7 } 1. & $\begin{array}{l}\text { Kesesuaian } \\
\text { materi }\end{array}$ & $62,50 \%$ & $100,00 \%$ & $62,50 \%$ & $93,75 \%$ & $100,00 \%$ & $100,00 \%$ \\
2. & Penyajian & $65,00 \%$ & $90,00 \%$ & $60,00 \%$ & $95,00 \%$ & $80,00 \%$ & $95,00 \%$ \\
3. & Kebahasaan & $50,00 \%$ & $100,00 \%$ & $75,00 \%$ & $100,00 \%$ & $87,50 \%$ & $87,50 \%$ \\
4. & Kompetensi & $62,50 \%$ & $93,75 \%$ & $56,25 \%$ & $87,50 \%$ & $87,50 \%$ & $100,00 \%$ \\
\hline & \multirow{2}{*}{ Kriteria } & Baik & $\begin{array}{c}\text { Sangat } \\
\text { Baik }\end{array}$ & \multirow{2}{*}{ Baik } & Sangat & Sangat & Sangat \\
& & & & & & Baik & Baik \\
\hline
\end{tabular}

Tabel 5. Kelayakan Angket Karakter

\begin{tabular}{llc}
\hline No. & \multicolumn{1}{c}{ Aspek } & Presentase \\
\hline 1. & Aspek menunjukkan sikap religius dalam pembelajaran. & $87,50 \%$ \\
2. & Aspek menampilkan perilaku kejujuran dalam pembelajaran. & $87,50 \%$ \\
3. & Aspek menunjukkan sikap toleransi dalam pembelajaran. & $100,00 \%$ \\
4. & Aspek menunjukkan tindakan disiplin dalam pembelajaran. & $90,00 \%$ \\
5. & Aspek menampilkan perilaku kerja keras dalam pembelajaran. & $87,50 \%$ \\
6. & Aspek menunjukkan sikap mandiri dalam pembelajaran. & $87,50 \%$ \\
\hline
\end{tabular}


Volume 2 Nomor 2, Edisi Desember 2019

Prodi PGSD Universitas Slamet Riyadi

ISSN 2620-6560 (print) ISSN 2620-746X (online)

7. Aspek menunjukkan sikap rasa ingin tahu dalam pembelajaran. $100,00 \%$

8. Aspek menunjukkan berpikir kreatif dalam pembelajaran. 100,00\%

9. Aspek menunjukkan tindakan berbahasa /komunikatif dalam pembelajaran. $\quad 87,50 \%$

10. Aspek menunjukkan sikap cinta damai dalam pembelajaran. 100,00\%

11. Aspek menunjukkan kebiasaan gemar membaca dalam pembelajaran. $\quad 87,50 \%$

12. Aspek menunjukkan sikap peduli lingkungan. $\quad 87,50 \%$

13. Aspek menunjukkan sikap tanggung jawab dalam pembelajaran. $\quad 100,00 \%$

Kriteria

Tabel 6. Tanggapan Guru Kelas IV

\begin{tabular}{cccc}
\hline No. & Sekolah & Skor Penilaian & Kriteria \\
\hline 1. & SD N Sawah Besar 02 Semarang & $86,67 \%$ & Sangat Baik \\
2. & SD Islam Plus Muhajirin Semarang & $100,00 \%$ & Sangat Baik \\
3. & SD N Siwalan Semarang & $96,67 \%$ & Sangat Baik \\
\hline
\end{tabular}

Tabel 7. Tanggapan Siswa Kelas IV B SD N Sawah Besar 02 Semarang

\begin{tabular}{cccc}
\hline Kode & Skor & Kode & Skor \\
\hline S-1 & 9 & S-14 & 10 \\
S-2 & 10 & S-15 & 10 \\
S-3 & 9 & S-16 & 10 \\
S-4 & 10 & S-17 & 10 \\
S-5 & 10 & S-18 & 10 \\
S-6 & 9 & S-19 & 9 \\
S-7 & 10 & S-20 & 10 \\
S-8 & 10 & S-21 & 10 \\
S-9 & 7 & S-22 & - \\
S-10 & 10 & S-23 & 10 \\
S-11 & - & S-24 & 10 \\
S-12 & 9 & S-25 & 10 \\
S-13 & - & &
\end{tabular}

Perhitungan Nilai Presentase Total $=96,36 \%$

Tabel 8. Tanggapan Siswa Kelas IV A SD Islam Plus Muhajirin Semarang

\begin{tabular}{cccc}
\hline Kode & Skor & Kode & Skor \\
\hline S-1 & 10 & S-13 & 10 \\
S-2 & 10 & S-14 & 7 \\
S-3 & 10 & S-15 & 10 \\
S-4 & 10 & S-16 & - \\
S-5 & - & S-17 & 10 \\
S-6 & 10 & S-18 & 10 \\
S-7 & 10 & S-19 & 10 \\
S-8 & 10 & S-20 & 10 \\
S-9 & 5 & S-21 & 10 \\
S-10 & 7 & S-22 & 10 \\
S-11 & 10 & S-23 & 8 \\
S-12 & 10 & S-24 & 9
\end{tabular}

Perhitungan Nilai Presentase Total $=93,64 \%$

Tabel 9. Nilai Karakter Siswa Kelas IV B SD N Sawah Besar 02 Semarang

\begin{tabular}{llcc}
\hline No. & \multicolumn{1}{c}{ Aspek } & Presentase & Kriteria \\
\hline 1. & Religius & $97,92 \%$ & Sangat Baik \\
2. & Jujur & $89,58 \%$ & Sangat Baik
\end{tabular}




\begin{tabular}{lllc} 
3. & Toleransi & $86,81 \%$ & Sangat Baik \\
4. & Disiplin & $86,88 \%$ & Sangat Baik \\
5. & Kerja Keras & $84,38 \%$ & Sangat Baik \\
6. & Mandiri & $78,65 \%$ & Baik \\
7. & Rasa Ingin Tahu & $72,40 \%$ & Baik \\
8. & Kreatif & $76,04 \%$ & Baik \\
9. & Berbahasa/komunikatif & $87,50 \%$ & Sangat Baik \\
10. & Cinta Damai & $90,63 \%$ & Sangat Baik \\
11. & Gemar Membaca & $72,92 \%$ & Baik \\
12. & Peduli Lingkungan & $91,15 \%$ & Sangat Baik \\
13. & Tanggung Jawab & $83,33 \%$ & Sangat Baik \\
\hline
\end{tabular}

Tabel 10. Nilai Karakter Siswa Kelas IV A SD Islam Plus Muhajirin Semarang

\begin{tabular}{llcl}
\hline No. & \multicolumn{1}{c}{ Aspek } & Presentase & Kriteria \\
\hline 1. & Religius & $94,32 \%$ & Sangat Baik \\
2. & Jujur & $92,05 \%$ & Sangat Baik \\
3. & Toleransi & $82,20 \%$ & Sangat Baik \\
4. & Disiplin & $87,05 \%$ & Sangat Baik \\
5. & Kerja Keras & $88,64 \%$ & Sangat Baik \\
6. & Mandiri & $82,39 \%$ & Sangat Baik \\
7. & Rasa Ingin Tahu & $80,68 \%$ & Sangat Baik \\
8. & Kreatif & $84,66 \%$ & Sangat Baik \\
9. & Berbahasa/komunikatif & $88,07 \%$ & Sangat Baik \\
10. & Cinta Damai & $88,64 \%$ & Sangat Baik \\
11. & Gemar Membaca & $82,95 \%$ & Sangat Baik \\
12. & Peduli Lingkungan & $89,77 \%$ & Sangat Baik \\
13. & Tanggung Jawab & $85,23 \%$ & Sangat Baik \\
\hline
\end{tabular}

Pengembangan media CD Alam dengan Kompetensi Dasar 3.2 interaktif macromedia flash berbasis Membandingkan siklus hidup nilai karakter merupakan suatu produk media berupa aplikasi beberapa jenis makhluk hidup serta berbasis teknologi. Materi yang mengaitkan dengan upaya pelestariannya. Untuk pembelajaran 2 terdapat pada media CD interaktif macromedia flash berbasis nilai karakter dalam pembelajaran 1 memuat dua materi pembelajaran. Diantaranya Bahasa Indonesia dengan Kompetensi Dasar 3.6 Menggali isi dan amanat puisi yang disajikan secara lisan dan tulis dengan tujuan untuk kesenangan, Ilmu Pengetahuan memuat tiga materi pembelajaran yaitu Seni Budaya dan Prakarya dengan Kompetensi Dasar 3.3.2 Mengetahui tanda tempo dan tinggi rendah nada, Bahasa Indonesia dengan Kompetensi Dasar 3.6 Menggali isi dan amanat puisi yang disajikan secara lisan dan tulis dengan tujuan untuk kesenangan, 
serta Ilmu Pengetahuan Alam dengan Kompetensi $\quad$ Dasar $\quad 3.2$ Membandingkan siklus hidup beberapa jenis makhluk hidup serta mengaitkan dengan upaya pelestariannya. Media dilengkapi dengan ilustrasi gambar dan video animasi disesuaikan dengan kebutuhan siswa. Pada desain cover media, peneliti menggunakan gambar yang diedit menggunakan aplikasi coreldraw $X 5$ dan demo animasi bergerak. Desain cover dan warna dibuat semenarik mungkin agar siswa tertarik untuk membaca materi dan berujung pada penanaman nilai karakter.

Uji kelayakan melibatkan 4 dosen ahli sesuai dengan kajian materi pada media CD interaktif macromedia flash berbasis nilai karakter yaitu Dosen ahli IPA SD sebagai validator media 1 dan materi 1, Dosen Ahli Bahasa Indonesia SD sebagai validator media 2 dan materi 2, dan Dosen Ahli SBdP SD sebagai validator media 3 dan materi 3 serta Dosen Ahli Karakter SD sebagai validator karakter. Analisis kelayakan media menggunakan kriteria pemilihian media yang dikemukakan oleh Kustandi \& Bambang, (2013: 78-89) yang meliputi aspek psikologis, organisasi isi, penyajian, enggunaan media, prinsip audio visual dan prisnip komputer, sedangkan analisis kelayakan materi didasarkan pada BNSP 2016 Kurikulum 2013 yang dirangkum meliputi aspek indikator kesesuaian materi, penyajian, kebahasaan dan kompetensi. (BNSP: 2016).

Rumus perolehan uji kelayakan diperoleh dari penilaian masing masing komponen yaitu dengan cara skor yang diperoleh dibagi dengan skor maksimal dan kemudian dikali 100\%. Perolehan nilai validasi kelayakan media 1 tahap I sebesar $63,75 \%$ dengan kriteria "baik" dengan syarat revisi. . Perbaikan produk media berdasarkan saran validator, maka dilakukan validasi media 1 tahap II sebesar $95,00 \%$ dengan kriteria "sangat baik". Kelayakan media 2 tahap I memperoleh $61,25 \%$ dengan kriteria "baik" dengan syarat revisi. Perbaikan produk media berdasarkan saran validator, maka dilakukan validasi media 2 tahap II sebesar 96,25\% dengan kriteria "sangat baik". 
Tahapan validasi media 3 tahap I memperoleh nilai presentase sebesar $68,75 \%$ dengan kriteria "baik". Perbaikan produk media berdasarkan saran validator, maka dilakukan validasi media 3 tahap II sebesar 91,25\% dengan kriteria "sangat baik". Uji kelayakan materi memperoleh nilai presentase $61,67 \%$ dengan kriteria "baik" pada materi 1 tahap I dengan revisi, maka dilanjutkan penilaian materi 1 tahap II memperoleh nilai $95 \%$ dengan kriteria "sangat baik". Kelayakan materi 2 tahap I sebesar $61,67 \%$ dengan kriteria "baik" dengan revisi, maka dilanjutkan penilaian materi 2 tahap II memperoleh nilai $93,33 \%$ dengan kriteria "sangat baik". Validasi materi 3 tahap I mempereoleh nilai presentase $88,33 \%$ dengan kriteria "baik" dengan revisi, maka dilanjutkan penilaian materi 3 tahap II memperoleh nilai $96,67 \%$ dengan kriteria "sangat baik". Nilai validasi rata-rata media secara keseluruhan memperoleh 92,46\% dengan kriteria "sangat baik" rata-rata validasi materi sebesar $91,31 \%$.
Uji kelayakan angket karakter mendapat persentase skor yang meliputi aspek menunjukkan sikap religius dalam pembelajaran $87,50 \%$, aspek menampilkan perilaku kejujuran dalam pembelajaran $87,50 \%$, aspek menunjukkan sikap toleransi dalam pembelajaran $100 \%$, aspek menunjukkan tindakan disiplin dalam pembelajaran 90,00\%, aspek menampilkan perilaku kerja keras dalam pembelajaran $87,50 \%$, aspek menunjukkan sikap mandiri dalam pembelajaran $\quad 87,50 \%, \quad$ aspek menunjukkan sikap rasa ingin tahu dalam pembelajaran 100\%, aspek menunjukkan berpikir kreatif dalam pembelajaran $\quad 100 \%, \quad$ aspek menunjukkan tindakan berbahasa atau komunikatif dalam pembelajaran $87,50 \%$, aspek menunjukkan sikap cinta damai dalam pembelajaran $100 \%$, aspek menunjukkan kebiasaan gemar membaca dalam pembelajaran $87,50 \%$, aspek menunjukkan sikap peduli lingkungan $87,50 \%$ dan aspek menunjukkan sikap tanggung jawab dalam pembelajaran $100 \%$. Sehingga hasil analisis penilaian validasi karakter mendapat presentase skor 
total sebesar $91,67 \%$ dengan kriteria baik sekali sehingga angket layak digunakan untuk pengambilan karakter.

Media CD interaktif macromedia flash berbasis nilai karakter memperoleh kriteria sangat layak pada tahap uji kelayakan maka dapat dilakukan tahapan uji coba lapangan yang dilakukan secara terbatas pada 3 Sekolah Dasar yang berada di lingkup Kota Semarang. Uji coba lapangan dilakukan untuk mengetahui keberterimaan media pada penggunaan proses pembelajaran. Perolehan keberterimaan media oleh guru memperoleh nilai di SD N Sawah Besar 02 sebesar 86,67\% dengan kriteria "sangat baik", SD Islam Plus Muhajirin memperoleh 100,00\% dengan kriteria "sangat baik" dan SD N Siwalan memperoleh 96,67\% dengan kriteria "sangat baik. Perolehan nilai presentase tanggapan siswa terhadap penggunaan media CD interaktif macromedia flash berbasis nilai karakter pada uji coba lapangan ialah sebesar 96,36\% di SD N Sawah Besar 02 dan 93,64\% di SD Islam Plus Muhajirin.
Dari data yang didapatkan di SD N Sawah Besar 02 dan SD Islam Plus Muhajirin menunjukkan aspek rasa ingin tahu yang mendapatkan presentase rendah, dan aspek religius mendapatkan presentase yang tinggi. Pada SD N SD N Sawah Besar 02 aspek rasa ingin tahu memperoleh presentase skor $72,40 \%$ yang merupakan presentase terendah. Hal ini dilihat dari indikator aspek rasa ingin tahu yang tidak terpenuhi, dimana saat pembelajaran berlangsung dengan menggunakan media ada anak yang tidak faham dengan media tersebut, kemudian anak kurang berinisiatif bertanya ketika tidak paham dengan materi. Sementara itu, aspek religius mendapatkan persentase skor $97,92 \%$ yang merupakan presentase tertinggi. Terlihat saat anak tersebut menunjukkan sikap selalu berdoa sebelum dan sesudah pembelajaran menggunakan media $\mathrm{CD}$ interaktif macromedia flash berbasis nilai karakter. Pada SD Islam Plus Muhajirin aspek rasa ingin tahu memperoleh persentase skor $80,68 \%$ yang merupakan presentase terendah. Terlihat dalam melaksanakan 
pembelajaran dengan menggunakan media ada anak yang menganggap materi terlalu mudah, sehingga tidak perlu bertanya lebih lanjut . Sedangkan aspek religius mendapatkan presentase skor $94,32 \%$ yang merupakan presentase tertinggi. Terlihat saat anak tersebut menunjukkan sikap selalu berdoa sebelum dan sesudah pembelajaran menggunakan media $\mathrm{CD}$ interaktif macromedia flash berbasis nilai karakter.

Keunggulan dari produk media $\mathrm{CD}$ interaktif macromedia flash berbasis nilai karakter terletak pada demo animasi yang bergerak dan evaluasi pembelajaran yang menggunakan desain gambar yang menarik serta media berbasis nilai karakter. Bentuk kemasan media berupa file, menjadikan media $\mathrm{CD}$ interaktif macromedia flash berbasis nilai karakter mudah disimpan, mudah dibawa kemanapun dan bahkan dapat di operasikan di handphone.

\section{SIMPULAN}

Berdasarkan dari hasil penelitian dan pengembangan yang telah dilakukan oleh peneliti, maka dapat diambil kesimpulan berupa dihasilkannya produk pengembangan media CD interaktif macromedia flash berbasis nilai karakter yang layak untuk digunakan untuk menanamkan nilai karakter materi subtema 1 aku dan cita-citaku kelas IV Sekolah Dasar. Kelayakan produk media tersebut, diperoleh berdasarkan tahapan proses pengembangan berupa nilai tolak ukur kelayakan media oleh Dosen validator ahli media, ahli materi pembelajaran dan ahli karakter yang berkompeten dalam bidangnya. Nilai kelayakan media CD interaktif macromedia flash berbasis nilai karakter oleh Dosen validator ahli memperoleh nilai kelayakan media dengan rata-rata secara keseluruhan sebesar 94,17\%， 95,00\% untuk kelayakaan materi pembelajaran dan 91,67\% untuk kelayakan nilai karakter .

Media CD interaktif macromedia flash berbasis nilai karakter pada tahap uji coba lapangan 
telah memperoleh nilai tanggapan guru atas keberterimaan media secara keseluruhan sebesar 96,67\% dengan kreteria "sangat baik" dan menyatakan bahwa media CD interaktif macromedia flash berbasis nilai karakter sangat layak digunakan. Hasil angket tanggapan siswa menyatakan bahwa 95\% siswa setuju dengan penggunaan media $\mathrm{CD}$ interaktif macromedia flash berbasis nilai karakter dapat memberikan kemudahan pemahaman materi secara mendalam, menumbuhkan nilai karakter yang dapat terintegrasi dalam media CD interaktif macromedia flash berbasis nilai karakter. Dengan demikian, pembiasaan karakter dapat melalui media CD interaktif macromedia flash berbasis nilai karakter.

Setelah dilakukan penelitian, saran yang dapat peneliti sampaikan adalah sebagai berikut:

1. Pada saat uji pengembangan, peralatan pembelajaran perlu dipersiapkan dengan sebaikbaiknya agar pada saat pembelajaran tidak terjadi suatu hal yang dapat menggangu pelaksanaan pembelajaran dengan media $\mathrm{CD}$ interaktif macromedia flash berbasis nilai karakter.

2. Media CD interaktif macromedia flash berbasis nilai karakter dapat digunakan untuk penelitian tahap lanjutan.

3. Pada tahap pengembangan produk media pada penelitian selanjutnya, diharapkan dapat memilih berbagai sumber gambar referensi sebagai pendukung dari materi subtema 1 aku dan cita-citaku.

\section{DAFTAR PUSTAKA}

Anggra. 2008. Memahami Teknik Dasar Pembuatan Game Berbasis Flash. Jogjakarta: Gava Media.

Arikunto, Suharsimi. 2013. Prosedur Penelitian Suatu Pendekatan Praktik. Jakarta: PT RINEKA CIPTA.

Arsyad, Azhar. 2014. Media Pembelajaran. Jakarta: Raja Grafindo Persada.

Kustandi, Cecep dan Bambang Sutjipto. 2013. Media Pembelajaran Manual dan Digital. Bogor: Ghalia Indonesia.

Kusumawati, Naniek. 2015. Pengembangan Media Pembelajaran IPA dengan Animasi Macromedia Flash Berbasis Model Pengajaran Langsung (Direct Instruction) 
Volume 2 Nomor 2, Edisi Desember 2019

Prodi PGSD Universitas Slamet Riyadi

ISSN 2620-6560 (print) ISSN 2620-746X (online)

Di Sekolah Dasar. Jurnal

Premiere Educandum 5 (2).

http://e-

journal.unipma.ac.id/index.ph

p/PE/article/download/289/26

1.

Diakses tanggal 21 November

2018.

Peraturan Menteri Pendidikan dan

Kebudayaan Republik

Indonesia Nomor 22 Tahun

2016 tentang Standar Proses

Pendidikan SD/MI.

Rusman. 2013. Belajar dan Pembelajaran Berbasis

Komputer: Mengembangkan Profesionalisme Guru Abad 21. Bandung: Alfabeta.

2015. Pembelajaran Tematik Terpadu Teori, Praktik, dan Penilaian. Jakarta: Rajawali Pers.

Sugiyono. 2017. Metode Penelitian Pendidikan Kuantitatif Kualitatif dan $R \quad \& \quad D$. Bandung: Alfabeta. 